\title{
The role of prevention and curative treatment in the elimination of malnutrition: a retrospective study based on the MSF program against malnutrition in GUIDAM ROUMDJI NIGER Republic.
}

\author{
Article by Hippolyte Ten, Pascal Nii Atanga \\ MPH, Texila American University, South Sudan \\ Email: hipten@yahoo.com
}

\begin{abstract}
This study is a retrospective description of the phenomenon of malnutrition in the district of Guidam Roumdji in the Maradi Region of Niger Republic, and a quantitative as well as qualitative analysis of the impact of a malnutrition program ran by the international medical organization Medicines Sans Frontieres within the same area and timeframe. Niger republic is an Islamic country in the Sahel region of West Africa with a prolonged history of famine and nutritional crisis over the past 25 years. From January to December 2012, a population of 2987 cured children aged 6-59 months and without sex differentiation was discharged from the ambulatory therapeutic feeding center. A sample of 520 of them was used to estimate the average weight gain (AWG) and average length of stay (ALS), the two most important indicators of program success. Observations included a cure rate of over $86.9 \%, 0.8 \%$ death rate, $4.5 \%$ default, 3.8\% transfer and $4.0 \%$ non-respondents. Results also revealed an AWG of $6.4 \mathrm{~g} / \mathrm{kg} /$ day and an ALS of 33.14 days and both were far above expectations thus confirming the effectiveness of the program. Using a z-test under 5\% significance rate and considering a one tail side confidence interval, the sample AWG and ALS were found not to be significantly different from their population counterpart, thus in support of an effective program performance at the population level. A further qualitative analysis of the causes of defaulting implicate the low societal status occupied by the women leading to the conclusion that women empowerment in Niger will help improve compliance to treatment and maximize the overall outcome of such program. In conclusion achieving prevention lies on empowering the women while curative treatment is the responsibility of the well-established medical programs ran under government scrutiny.
\end{abstract}

$\begin{array}{ll}\text { Abbreviations } \\ \text { ALS } & \text { Average length of stay } \\ \text { AR } & \text { Attendance rate } \\ \text { ARI } & \text { Acute respiratory tract infections } \\ \text { ATFC } & \text { Ambulatory therapeutic feeding center } \\ \text { AWG } & \text { Average Weight gain } \\ \text { BMR } & \text { Basal metabolic rate } \\ \text { CR } & \text { Cure rate } \\ \text { CRENAS } & \text { Centre de rehabilitation national pour ambulatories severe } \\ \text { DfR } & \text { Defaulter rate } \\ \text { GAM } & \text { Global acute malnutrition } \\ \text { GR } & \text { Guidam Roumdji } \\ \text { Ha } & \text { Alternate hypothesis } \\ \text { HIV } & \text { Human immunodeficiency virus } \\ \text { H0 } & \text { Null hypothesis } \\ \text { ITFC } & \text { Intensive therapeutic feeding program } \\ \text { MAM } & \text { Moderate acute malnutrition } \\ \text { MIC } & \text { Measles immunization coverage } \\ \text { MMR } & \text { Mortality morbidity review } \\ \text { MSFB } & \text { Medicines Sans Frontieres Belgium }\end{array}$


South American Journal of Public Health

Special Edition May 2016

$\begin{array}{ll}\text { MUAC } & \text { Mid upper arm circumference } \\ \mathrm{Nb} & \text { number } \\ \text { NGO } & \text { Non-governmental organization } \\ \text { SAM } & \text { Severe acute malnutrition } \\ \text { SFC } & \text { Supplementary feeding center } \\ \text { TB } & \text { tuberculosis } \\ \text { UNICEF } & \text { United nations children fund } \\ \text { W } & \text { weight } \\ \text { WG } & \text { Weight gain } \\ \text { W/H } & \text { Weight for height ratio } \\ \text { FUO } & \text { Fever of unknown origin }\end{array}$

\section{Introduction}

\section{a) Background}

In year 2000, several countries met in an assembly known as the millennium summit and fixed some targets or objectives achievable by the year 2015. These objectives are widely known as the millennium developmental goals and are eight (8) in number. The first MDG deals with eradication of poverty and hunger. Hunger leads to under nutrition whose characteristics include malnutrition, a condition that results from eating a diet in which nutrients are either not enough or too much. Nine months into 2015, malnutrition is still rampant in several parts of the world especially in the Sahel region of the Sub-Saharan Africa. It is thus important to understand why malnutrition is persistent in this region.

Several organizations have dedicated themselves to the fight against malnutrition and over the years have been managing programs whose main aims is to reduce the morbidity and mortality caused by this disease. Eradication is not attainable due to the ongoing consequences of climate change so this study will concentrate on elimination, which is still attainable and realistic.

\section{b) Problem}

1)Why is it that despite all the multiple interventions still taking place in the Sahel region, malnutrition remains resistant in some areas? 2) Is failed elimination due to the ineffectiveness of those standard therapeutic programs targeting curative treatment of severely malnourished children? 3) Are there some structural factors embedded in the culture of the affected populations responsible for the chronic cases of this ailment? 4) What is the best strategy to achieve elimination?

\section{c) Study rationale}

1) Malnutrition is one of the five main causes of under-5 mortality in sub-Saharan Africa. 2) The economic burden of malnutrition is very high considering the financial cost of therapeutic foods, the number of school hours lost by the malnourished patients and the reduced productivity in parents of affected children. 3) The fight against poverty and hunger is a specific target in the first millennium development goal developed by the United Nations General Assembly.

\section{d) Study objectives}

\section{General objective}

To raise awareness on the importance of combining both curative treatment and prevention in the fight against malnutrition as most studies usually concentrate on one of the aspects only.

Specific objectives

1) To present Medicines sans frontiers (MSF) as a leading international medical organization in the treatment of severe acute malnutrition

2) To highlight the indicators for a successful ambulatory therapeutic feeding program 
3) 3)To single out defaulting and propose qualitative solutions to influence this unfavorable outcome.

4) To emphasize women empowerment as a needed societal change capable of reducing malnutrition in Niger Republic.

5) To introduce climate change as a forthcoming challenge in the fight against malnutrition especially in the Sahel region of Africa

\section{Literature Review}

Malnutrition being an old subject, it is paramount to look into past proposition of solutions in the literature

\section{2- Literature review for concepts and theories on malnutrition.}

The word malnutrition originated between 1860-65 from mal + nutrition (CRandom House. Inc., 2015). Malnutrition derived from mal + nutrition in 1843 (C) 2010 Douglas Harper, 2015). Malnutrition is the lack of adequate nutrition resulting from insufficient food, unbalanced diet or defective assimilation (Harper Collins, 2004). Malnutrition is poor nutrition due to insufficient or poorly balanced diet, faulty digestion or food utilization (Houghton Miffin Company, 2005). It may affect calories, proteins, carbohydrates, minerals or vitamins (Young, 2012, page 36-38) and manifests as either under nutrition or overnutrition. The former characterizes insufficiency in the aforementioned nutrients while the latter reflects an excess (UNICEF, 2010, Page 61 and 75). For the purpose of this study, malnutrition represents under nutrition, which comprises protein energy (PEM) malnutrition and macronutrients deficiency. PEM includes marasmus, kwashiorkor and Marasmickwashiokor. Examples of macronutrients deficiencies are pellagra, rickets, scurvy and beriberi to mention but a few.

Marasmus' path physiology reveals a combined deficiency in proteins and energy. Main changes include reduced basal metabolic rate, hyponatremia, hypokalemia, and proteolysis. Additional cardiac and renal changes consist of reduced cardiac output/ systolic volume as well as decrease glomerular filtration. A very important finding is that of loss of body temperature control culminating into temperature instability characterized by periods of hypothermia alternating with hyperthermia. Consider shock if temperature instability ensues. A pathognomonic common clinical feature is wasting with the patient having the appearance of an old man because of profound loss of muscular as well as fat tissues in the entire body. Others are lethargy, loss of reflexes, diarrhea, hypo/hyperpigmentation, conjunctiva pallor, and scaphoid abdomen.

Kwashiorkor is another variant of malnutrition in children but its pathophysiology remains unclear. The etiology kwashiorkor is truly not known and three hypotheses have been proposed so far but none was finally retained. The first hypothesis considers a diet poor in some macro and micronutrients but this is not enough to explain the change in capillary permeability with reduced oncotic pressure and hypernatremia causing the pedal edema that is characteristic of this disease. The second hypothesis is associated with deterioration in the vanadium metabolism leading to capillary permeability. The third one relates the edema of kwashiorkor to the increase oxidative stress that is common in kwashiorkor children. It is much more severe compare to marasmus and increases mortality in the intensive therapeutic feeding center. Clinical management is challenging and potentially dreadful for health workers lacking experience in malnutrition.

The third form is a combination of both known as marasmic-kwashiorkor. Cases present with signs from both marasmus and kwashiorkor.

Another hypothesis for Kwashiorkor is oxidative stress but it is not clear how this produces edema. It resulted from the study that discovered the implication of oxidants that it is sometimes very difficult to translate findings from research units and academic centers into practical guidelines. (Golden, 2002, page 5). It is paramount to improve communication 
South American Journal of Public Health

Special Edition May 2016

between academicians actively researching on severe malnutrition and humanitarian workers for the benefits of refugees and famine relief operations.

Prevention is the action of protecting self in advance against a particular phenomenon. It is a way of anticipating the development of something and working hard to avoid it. Prevention is the essence of public health, which divides it into three different categories according to the levels of care. Primary prevention mainly deals with health education while secondary main concerns are early diagnostic and prompt treatment. Tertiary prevention ensures rehabilitation into the society. Common activities directed towards the prevention of malnutrition in children are various food distributions (general food distribution, targeted food distribution, supplementary food distribution, etc...). Baby friendly clinic programs advocate for more exclusive breastfeeding for at least six months and protect neonates from becoming malnourished. Special groups such as pregnant and lactating women, elderly and orphans are part of highly vulnerable groups, thus managed with extra care. Agriculture and increase financial power are also necessary. New programs such as food for cash are becoming very popular. Recent developments in the field of climate change also establish a strong relationship between droughts and famine.

Eradication is the action of uprooting, extirpating or annihilating. It is a very difficult thing and requires many efforts. It is very common in the medical jargon and usually applied in the fight against diseases. Chicken pox, poliomyelitis have been eradicated in some parts of the world. The first millennium developmental goals targeted the eradication of malnutrition by 2015 but unfortunately half way into the year reports instead suggest a worsening of the situation due to consequences of natural disasters and increased poverty in some parts of the world. Elimination is the action of casting out or pushing away from the door or limit. It reduces the phenomenon up to an acceptable level where it is no more a threat for the public. It is not permanent and there is always a possibility of reappearance if there is a supportive environment. We can cite the case of Liberia, which was declared Ebola free two months ago but recently, started producing new cases of the disease again. Poliomyelitis was eliminated in some parts of Africa but sporadic cases are still recorded overtime. It is thus safer to consider eliminating malnutrition rather than eradicating it.

\section{3- Literature Review on previous research results.}

$<$ Niger: Too Little, Too Late $>$ (Potts \& Gidi \& Campbell \& Zureick, 2011, page 1) is an article by Malcolm Potts, Virginia Gidi, Martha Campbell and Sarah Zureick, which was published on the journal of international perspectives on sexual reproduction and reproductive health, volume 37, number 2, June 11. The introductory line is a question by Lord Adair Turner: "How is Niger going to feed a population growing from 11 million today to 50 million in 2050 in a semi-arid country that may be facing adverse climate change is unclear."(Potts \& Gidi \& Campbell \& Zureick, 2011 as cited by Turner, 2011, page 3). With the fastest growing population and a total fertility rate of 7.4 births per woman, Niger will surely be soon overpopulated and even the limited arable land with disaster forcing people to move into big cities where food is already insufficient. Among the poorest countries (174 out of 178 in the developmental index) in the world, Niger also faces very low education rate, worst in females, limited rainfalls and challenging environmental changes. It is the country most affected by malnutrition in the Sahel region. An estimated 10 million Nigeriens suffered food shortages in 20121. Market prices are very high for the average Nigerien and the government has no policy change for the nearest feature. The United Nations environment program predictions are that of an environmental disaster in the Sahel region because of global warming. The implementation of family planning coupled with the increase of the age of marriage for females are two strategies that could help stabilize the population and control malnutrition. Good reproductive health can thus help to combat malnutrition.

In $<$ towards an integrated approach for addressing malnutrition in Zambia $>$, (Harris \& Drimmie, 2012, page v), Joddy Harris and Scott Drimie of the poverty health and nutrition division, carried out a literature review and institutional analysis to discover solutions for 
ending poverty and hunger in sub-Saharan Africa. The two analysts started by postulating that the majority of interventions against malnutrition over the years are direct interventions. They consist of either direct distribution of food in areas affected by food insecurity or therapeutic programs mainly characterized by drugs distribution. In this case, drugs also included therapeutic foods. This developmental approach tends to link malnutrition interventions only to the health sector. The aforementioned solution is not sustainable because of the complex interrelated determinants of malnutrition as outlined by the UNICEF's framework. Their proposition was that of an inter-sectorial approach which would consider other sectors such as agriculture. The two authors also acknowledged the lack of consensus on the implementation of the inter-sectorial approach. The absence of political support as well as inexistent collaboration between legitimate sectors appeared to be one of the major setbacks for the adoption of the newly proposed strategy. In the case of Zambia, however authors brought to our notice the existence of a rising movement known as SUN. SUN stands for 'scaling up nutrition' a concept that has started gaining the consideration of the government as well as many other political institutions. Despite the fact that, Zambia policy makers are becoming more and more aware of the importance of an intervention that considers inter-sectorial collaboration and communication, no concrete steps have been taking towards the implementation of a related policy and other countries need to look out for solutions applicable to their contexts. Development of agriculture together with health interventions are thus viable solutions for the eradication of malnutrition.

The analysis of an exploratory study on malnutrition in children realized in the slumps of Lahore Pakistan over three hundred and sixty one (361) children less than five (5), revealed through multiple logistic regressions that father's education, neonatal health, feeding practices, starvation as well as poor sanitation were all risks factors for malnutrition. It is of the resort of the government to provide such basic amenities. Adequate education, environmental health and neonatal health status are definitely important variables for malnutrition eradication.

Adverse environmental conditions such as environmental contamination (e.g. water pollution), ecosystem destruction, loss of biodiversity, climate change, and the effects of globalization have contributed to an increasing number of health hazards and all affect nutritional status. (BLÖSSNER, 2005, page 1, as cited by John \& Eyzaguirre, 2000). The rising sea levels affect the development of some species of fish that use to be part of the family menu in some countries. There is therefore a strong relationship between the environment and nutrition and we should strive to maintain sustainable and symbiotic rapports between those two.

\section{Methodology}

\section{a) Study area}

GR is the main town in the GR County, MARADI Region of the Niger Republic in West Africa. It is located $50 \mathrm{~km}$ away from MARADI along the West-North-West axis, and $500 \mathrm{~km}$ away from NIAMEY the capital city to the East. It is crossed by the national road N1 axis extending from NIAMEY-DOSSO-MARADI-ZINDER-DIFFA to NGUIGUI. Population was estimated to be about 88680 inhabitants with $99 \%$ of them coming from the HAUSA tribe and practicing Islam as their religion.

\section{b) Study population}

The studied universe was the total number of malnourished children that exited the program within the study area while the population consisted of cured malnourished children aged 6-59 months. The following were the inclusion criteria

- $\mathrm{W} / \mathrm{H}>-2 \mathrm{Z}$-scores on 2 consecutive weight measurements, 1 week apart

And

- Absence of oedema for at least 1 week

And 
South American Journal of Public Health

Special Edition May 2016

- Absence of acute medical problems, good appetite and food consumption

- And MUAC $>115 \mathrm{~mm}$

- And minimum of 3 weeks in the program

- Age 6-59 months

Cured children were those that exceeded their expected weight in phase 2, which represents the rehabilitation phase.

\section{c) Study duration.}

Data collection took place from the $1 / 2 / 2012$ to the $12 / 30 / 2012$ and the retrospective study extended from May-November 2015.

\section{d) Sampling method.}

Weekly data formed the sampling frame around which the overall sample derived from. Ten (10) cases from the total number of newly cured patients were continuously recruited randomly at the end of every week, using the faces of a coin for a total of 52 weeks, to complete the 2012 epidemiologic year. Patients were treated as ambulatory cases once a week and those who failed an appointment were considered as defaulters. Community workers looked for defaulters and tried to understand the reason why they did not come to the clinic then proposed viable solutions in order to ensure continuity in the treatment.

\section{e) Sample size (S)}

\section{$(\mathrm{S}=\mathbf{5 2 0})$}

Table 1: Monthly outcome indicators (on 6-59 months) - ATFC of CRENAS-GR-Niger-MSF12

\begin{tabular}{|l|c|c|c|c|c|c|c|}
\hline & Cured & $\begin{array}{c}\text { Transfer } \\
\text { other } \\
\text { NGO }\end{array}$ & Defaulter & $\begin{array}{c}\text { Transfer } \\
\text { out prog }\end{array}$ & $\begin{array}{c}\text { Non } \\
\text { respondent }\end{array}$ & Death & Total \\
\hline Jan & 113 & 2 & 4 & 0 & 1 & 0 & 120 \\
\hline Feb & 92 & 0 & 10 & 0 & 0 & 0 & 102 \\
\hline Mar & 123 & 0 & 6 & 0 & 1 & 2 & 132 \\
\hline Apr & 159 & 0 & 3 & 0 & 0 & 0 & 162 \\
\hline May & 255 & 0 & 18 & 0 & 2 & 0 & 275 \\
\hline Jun & 247 & 16 & 14 & 0 & 12 & 1 & 290 \\
\hline Jul & 258 & 0 & 19 & 0 & 21 & 0 & 298 \\
\hline Aug & 340 & 0 & 15 & 0 & 30 & 1 & 386 \\
\hline Sept & 376 & 0 & 20 & 0 & 23 & 4 & 423 \\
\hline Oct & 309 & 0 & 15 & 0 & 15 & 5 & 344 \\
\hline Nov & 403 & 0 & 15 & 0 & 23 & 10 & 451 \\
\hline Dec & 312 & 0 & 15 & 0 & 10 & 5 & 342 \\
\hline Total & 2987 & 18 & 154 & 0 & 138 & 28 & 3325 \\
\hline
\end{tabular}


South American Journal of Public Health

Special Edition May 2016

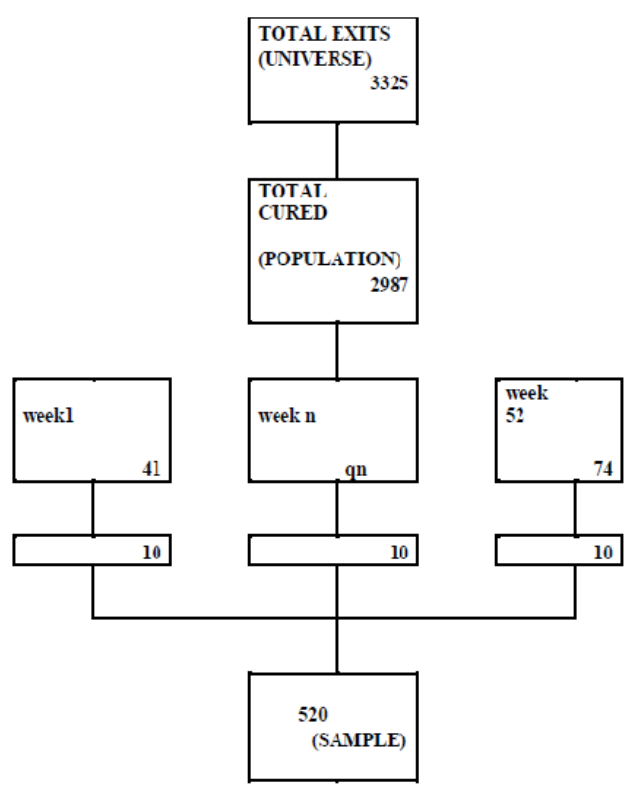

Sample statistics of importance included two means (average weight gain and average length of stay), three percentages (percentage of immunization, percentage of attendance, percentage of defaulters). Everything was put into place to avoid a random sampling error and statistics precision of 5\% was fixed as cutoff. Confidence level was assumed at least $95 \%$ due to the high reliability of the study, which took place over a year. The sampling distribution of means / proportions applied to the sample statistics considering conditions of normality for the population, confirmed that any potential errors was not related to the sampling technique used to get our selection.

\section{f) Study tools}

- TAU postgraduate thesis final report sample (Annex 9)

- Research Chronogram (Annex 10)

\section{g) Data collection}

This research made use of secondary data extracted from the MSF international database for malnutrition and the following lines explain all the processes involved in their collection.

The mainstay was the collection of anthropometric measurements including the weight, the height, and the mid-upper arm circumference. The presence or absence as well as the grading of edema were also very important. A senior trained staff member immediately reported these primary data into patient files during the admission process, and usually summarized them daily in the center registries. Encoding of these secondary data into the program datasheet (EPITOOLS) happened weekly and analysis by the data manager took place monthly. Age estimation and vaccination status confirmation were either from information reported on the immunization cards or using the findings obtained during history taking. Weight measurement (see annex 3) using weighing scales after cloths removal, was the standard practice. For children less than $15 \mathrm{~kg}$ (approximately 1 and $1 / 2$ year) measurement was taken using a basinet scale whereas for those whose weight was above $15 \mathrm{~kg}$ and unable to stand their weight was subtracted from the combined weight of the mother and her child. This process took place on the first day of admission and on each clinic day until discharge. Nutritional assistants performed these operations under my supervision. Throughout followup, measurements took place early in the morning precisely before $8 \mathrm{am}$. The recalibration of weighing scale was systematic after five subsequent measurements. Immediate recording on patients 'weight-monitoring charts was effective. 
Height measurement was either in supine position if child less than $85 \mathrm{~cm}$ (see annex 1) tall or standing if child's height was greater than $85 \mathrm{~cm}$ (see annex 2) and if he /she could walk and stand without support. Two operators simultaneously held the child head and leg straight along a measuring wooden board in order to obtain a good reading. The head was up and the feet down. The assistants were also responsible for immediately filling obtained readings into the children's' height monitoring charts.

A medical doctor later directly derived, the weight for height $(\mathrm{W} / \mathrm{Z})$ also known as the $\mathrm{Z}$ score, from a nomogram (Annex8) containing standard values for respective sexes, weights and height. The world health organization published the nomogram after extensive worldwide research and introduced it as the standard tool for assessing weight for height in children irrespective of their geographical origin.

During home visits as standard procedures for following up defaulters, trained health personnel from the community verbally asked specific questions aimed at clarifying reasons for not attending the clinic. A weekly written report later summarized the findings and most of them were qualitative in nature thus opening an avenue to appreciate some of the negative cultural practices.

Attendance reports recorded all the patients who attended the clinic at any time of the year.

\section{e) Data analysis}

The first step will consist of listing all measures and indices/indicators planned for the analysis. They will all be percentages/proportions representing the degree or extent of program results. These include the average weight gain, the average length of stay, the morbidities and mortalities, the immunization coverage, the percentage of transfer in, transfer out and cured. After listing all the parameters involved in the analysis, a temporal as well spatial distribution will follow to help appreciate the variations throughout year 2012. The 12 months lengthy period will confirm the reliability of the study over subsequent months, and strengthens its validity over some other experiments. The geographical origins of new cases will help indicate the spread of the phenomenon over the entire study area, represented here by the GR health district. After the distribution, a comparison of indicators against MSF/WHO standards will help reinforce the validity of the study. Case study, and past observations will help in a well-structured manner shade the light on the roles of society customs in maintaining malnutrition in that region and lay the foundation for the some postulates. The last step in the analysis will deal with the stated null hypothesis (H0) testing. The chosen significance level is $5 \%$ and sampling is through z-normal distribution. For probabilities calculation during $\mathrm{H} 0$ testing, a random sample of 520 cured children will be used. Z-test is the statistical tests that will help compare the success achieved in the population against that obtained with the sample. Two online statistical tools will be applied for the calculation of standard deviation (https://www.easycalculation.com/statistics/standarddeviation.php) and z-test between the population and the sample (http://insilico.net/tools/statistics/ztest)

\section{Observations and Findings}

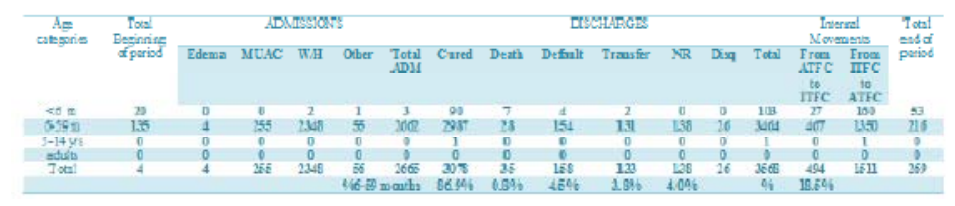

Figure 2: Movements and outcome indicators

\section{a) Movements}

The management of malnourished children (see annex8) usually consisted of several movements from screening, to admissions, discharges or internal movements (refer to ITFC 
from ATFC or vice-versa). Movements were usually well coordinated with trained national staffs under the supervision of expatriates' medical doctors.

\section{1) Admissions}

Admissions criteria were as follows:

- Age 0-14 years

- Bilateral pitting oedema

Or

- $\mathrm{W} / \mathrm{H}<-3$ z-scores2

Or

- $\mathrm{MUAC}<115 \mathrm{~mm}$ (for children with height between $65-110 \mathrm{~cm}$ )

Or

- referred from ITFC (internal movement, to complete phase 2 in ATFC)

- And

No medical complications, clinically alert, good appetite (refer to initial assessment below) Types of admissions

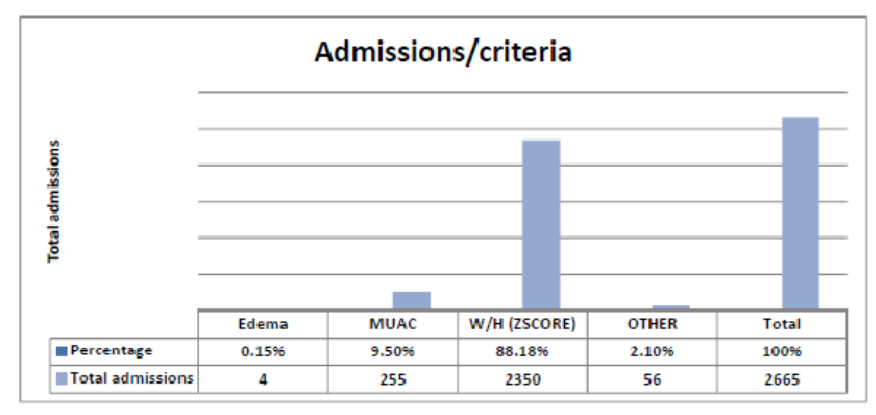

Figure 3

Overall 2665 children were admitted with 2662(99.98\%) between 6-59 months and 3 $(0.1 \%)<6$ months. On the 2662 aforementioned children $2348(88.20 \%)$ satisfied the $\mathrm{W} / \mathrm{H}$ criteria, $255(9.57 \%)$ had a MUAC less than $115 \mathrm{~mm}, 55$ (2.066\%) passed other criteria, and 4 $(0.15 \%)$ had developed edemas. The Z-score was thus the main criteria for admission, making results very reliable since based on the WHO nomogram for BMI in children. The nomogram is sex and age dependent with differences in measurements techniques based on whether the subject height is grater or less than $85 \mathrm{~cm}$. It also has the advantage of been applicable worldwide.

Origin of new admissions

\begin{tabular}{|c|c|c|}
\hline \multicolumn{3}{|c|}{ ORIGIN OF NEW ADMISSIONS } \\
\hline AREA & $n$ & $\%$ \\
\hline $0-5 K M$ & 558 & $21.6 \%$ \\
\hline 5-15 KM & 927 & $35.9 \%$ \\
\hline $15-30 \mathrm{KM}$ & 975 & $37.8 \%$ \\
\hline$>30 \mathrm{KM}$ & 120 & $4.7 \%$ \\
\hline TOTAL & 2580 & $100 \%$ \\
\hline
\end{tabular}

975(37.8\%) of the new admissions originated from an area $15-30 \mathrm{~km}$ away from the ATFC while $927(35.9 \%)$ came from a distance $5-15 \mathrm{~km}, 558(21.6 \%)$ came from localities $0-5 \mathrm{~km}$ away and $120(4.7 \%)$ had to travel more than $30 \mathrm{~km}$ to get to the center. This widespread distribution confirmed that the entire location was affected thus making the sample to be representative of the study area. 
South American Journal of Public Health

Special Edition May 2016

Admissions per age group

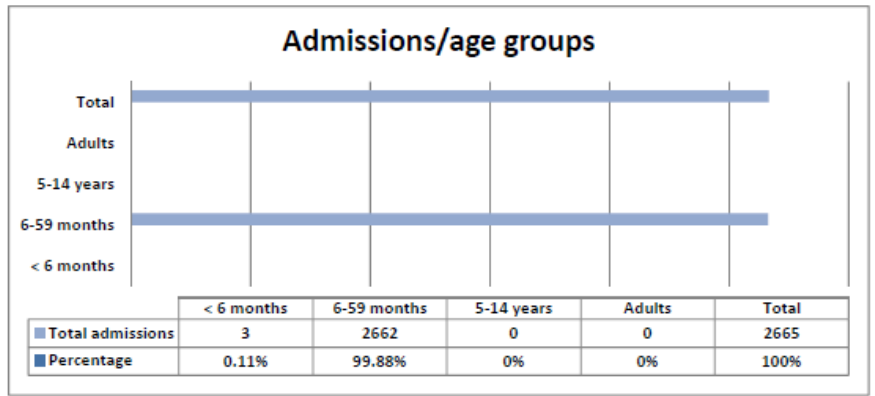

From the 2665 admissions 2580 (96.8\%) were new among which 2578 (99.92\%) came from children aged 6-59 months and $2(0.08 \%)$ from those less than 6 months.

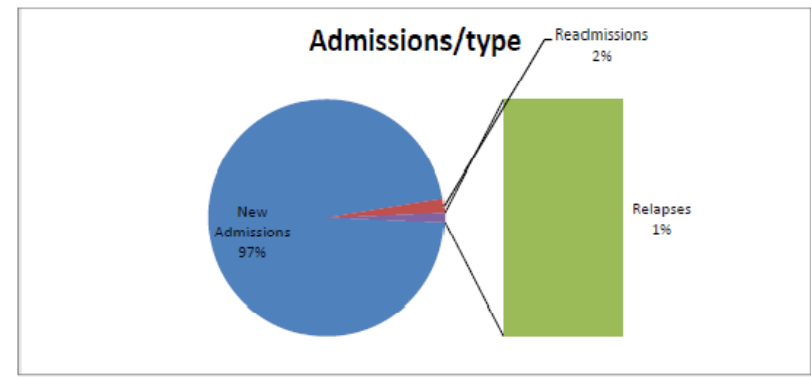

Figure 5: Re-admissions, direct admissions ATFC and internal transfers

The age group 6-59 months was more represented meaning results were in accordance with our study population. In the age group of interest, we had $2 \%$ readmissions distributed as $11(0.42 \%)$ readmissions after defaulting and $40(1.55 \%)$ readmissions after transfer. We recorded $33(1.28 \%)$ relapses.

\begin{tabular}{lll}
\hline \multicolumn{2}{l}{ Referral Of New Admissions } \\
\hline & $\mathrm{n}$ & $\%$ \\
\hline Spontaneous & 2555 & 99 \\
\hline Outreach & 25 & 1 \\
\hline Total & 2580 & 100 \\
\hline
\end{tabular}

Further analysis revealed that from the 2580 new admissions, 2555(99\%) were spontaneous and only $25(1.0 \%)$ arrived the ATFC through the help of our outreach team. This confirms the acceptability of our services by the host population most likely because of our outstanding results but also due to the longstanding history, MSF has had with Niger, as the main international actor in the fight against malnutrition in the Sahel region of West Africa

\section{2) Discharges}

Admissions, exits and number of beneficiaries

Exits $=$ discharges $=\Sigma$ (cured; deaths; defaulters; transfers; non-respondents; disqualified)

Beneficiaries $=$ all those who visited the ATFC and were supported one way or the other.

Figure6/ monthly distribution of Admissions, exits and number 


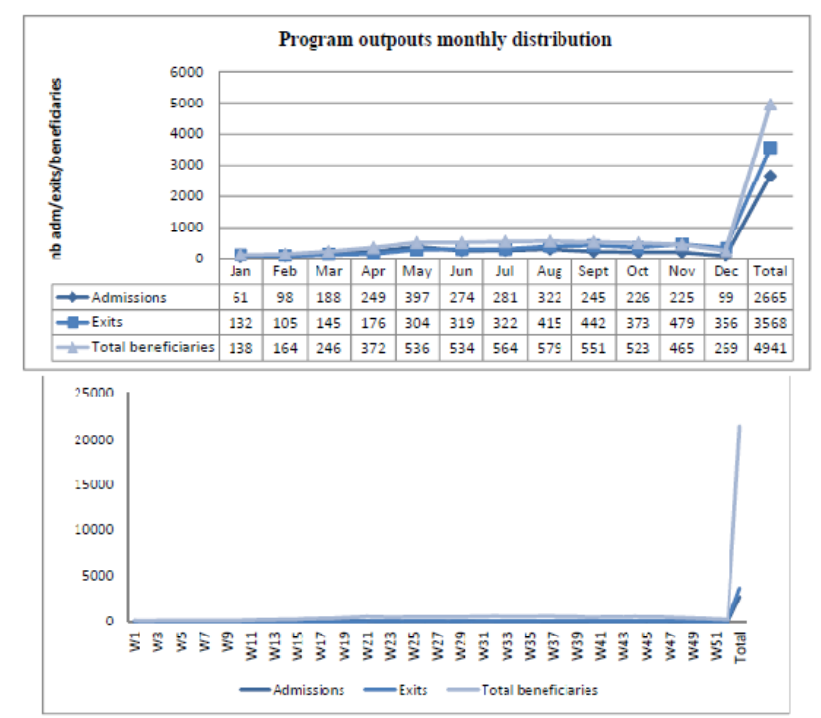

Figure 6/weekly distribution of Admissions, exits and number

3568 discharges were made all categories included and the age group 6-59 months accounted for $3464(97.085 \%)$, followed by the <6months $103(2.88 \%)$ and $5-14$ years $1(0.028 \%)$. The following is the distribution of the 3464 discharges from the age group of concern in our study: Cured 2987(86.22\%), Defaulters 154(4.44\%), Non-respondent 138(3.98\%), Transfer 131(3.78\%), Deaths 28(0.8\%) and Disqualified 26(0.75\%).

The category of cured cases aged 6-59 months was the most significant and represented our study population from which outcome indicators were calculated to evaluate the nutritional program. A child was only confirmed cured after medical review. The following are criteria that needed to be met for discharge as cured case.

- $\mathrm{W} / \mathrm{H}>-2 \mathrm{Z}$-scores on 2 consecutive weight measurements, 1 week apart

And

- Absence of oedema for at least 1 week

And

- Absence of acute medical problems, good appetite and food consumption

- And MUAC > $115 \mathrm{~mm}$

- And minimum of 3 weeks in the program

The total number of defaulters even though acceptable raises questions on the issues of patient follow-up.

The facts that several outreach teams are deployed daily into the community could implicate societal norms.

The review of over 15 reports by the social workers members of the outreach team revealed the following as main causes of defaulting:

(a) Multiple children sometimes preventing the mother to come to the therapeutic center with the sick child one

(b)Pregnancy can hinder movements and cause the mother to miss the ATFC clinic appointment of the malnourished child

(c) Sick child under the custody of the grandmother who is sometimes not diligent with clinic attendance

(d) Traditional events such as marriage during which the present wives must be deeply involved in the wedding ceremonies of the subsequent co-wives, sometimes causing them to forget their children clinic appointment

(e) Illiteracy rate is very high in Niger and worse in females causing mothers to sometimes misunderstand or misinterpret doctor's prescriptions and follow-up schedule

(f) Religion through compulsory attendance of the Friday service at the mosque was in some cases the main reason responsible for the absence at the clinic. 
(g) Poverty also forced some mother to go to farm instead of bringing children to clinic for their appointment.

(h)The society is patriarchal and after divorce, the children are sometimes handed over to a father who does not understand the need for the child to follow up with her/his treatment.

(i)Nomadic populations are known for their constant movements from one area to another, making it difficult for them to follow up with long-term treatment.

Non-respondent cases failed to meet the criteria for discharge after 12 consecutive weeks into the program and needed further evaluation to rule out some conditions e.g. tuberculosis,

cardiomyopathy, neurological disorders, congenital malformations, etc. Disqualification arose later for cases who were wrongly admitted into the program, most likely due to misinterpretation of the ZSCORE by novice.

Some deaths were recorded and no relationship could be established with malnutrition, but despite that the policy of the program required us to register those cases as mortalities.

\section{3) Internal movements}

\begin{tabular}{lcc}
\hline & \multicolumn{2}{c}{ Internal movements } \\
\hline Age Categories & From ATFC to ITFC & From ITFC to ATFC \\
\hline$<6$ months & $\mathbf{2 7}$ & $\mathbf{1 6 0}$ \\
\hline $6-59$ months & $\mathbf{4 6 7}$ & $\mathbf{1 3 5 0}$ \\
\hline Total & $\mathbf{4 9 4}$ & $\mathbf{2 6 9}$ \\
\hline
\end{tabular}

These referred to cases moved to the ITFC from the ATFC and vice-versa. In the group 659 months 467 patients were referred to the ITFC probably as result of the worsening of the medical conditions. Returnees from ITFC are generally stable medically with a good appetite therefore fit to continue nutritional rehabilitation as ambulatory patients. Several meetings between staffs working in both the ITFC and the ATFC were held every Friday and the main agenda consisted of improving referrals between both facilities. It is important to note that both structures were located within the same hospital. The main cause of internal transfers was the development of severe and acute medical complications, which required admissions into the intensive phase. Examples of these complications included acute watery diarrhea with moderate-severe dehydration, severe malaria, severe pneumonia, etc. Some rare cases move into the ITFC because of no weight gain despite good appetite. In the later cases the ITFC was an important tool for treatment monitoring and positive results while on admission suggested the mother either sold the therapeutic food of shared it among other siblings.

\section{4) Tracing of transfers}

\begin{tabular}{lll}
\hline Tracing of transfer & $6-59$ months & Total \\
\hline Transfer medical & $\mathbf{0}$ & $\mathbf{0}$ \\
\hline Transfer to other NGO's ATFC & $\mathbf{1 8}$ & $\mathbf{1 8}$ \\
\hline CRENAS-CRENAS & $\mathbf{1 1 0}$ & $\mathbf{1 1 0}$ \\
\hline
\end{tabular}

Following change of address 131 patients were transferred to other facilities with $18(13.74 \%)$ to other non-governmental organizations, $110(83.89 \%)$ to ATFC in other regions. Three transfers are unaccounted for, probably as result of missing data/information. Transfers were done formally with hand written letters. CRENAS-CRENAS represents transfers across several MSFB ATFCs since the nutritional program in Niger was made of several other projects such as SAISABOUA, SONGLOULOU (at the border with Nigeria), SABONG GARI, DAKORO, etc. Other NGOs we cooperated with included SAVE THE CHILDREN and ALIMA-BEFEN. 


\section{b) Outcomes}

\begin{tabular}{|l|l|l|l|l|l|l|l|}
\hline & Cured & $\begin{array}{c}\text { Transfer } \\
\text { other } \\
\text { NGO }\end{array}$ & Defaulter & $\begin{array}{c}\text { Transfer } \\
\text { out prog }\end{array}$ & $\begin{array}{c}\text { Non } \\
\text { respondent }\end{array}$ & Death & Total \\
\hline Jan & 113 & 2 & 4 & 0 & 1 & 0 & 120 \\
\hline Feb & 92 & 0 & 10 & 0 & 0 & 0 & 102 \\
\hline Mar & 123 & 0 & 6 & 0 & 1 & 2 & 132 \\
\hline Apr & 159 & 0 & 3 & 0 & 0 & 0 & 162 \\
\hline May & 255 & 0 & 18 & 0 & 2 & 0 & 275 \\
\hline Jun & 247 & 16 & 14 & 0 & 12 & 1 & 290 \\
\hline Jul & 258 & 0 & 19 & 0 & 21 & 0 & 298 \\
\hline Aug & 340 & 0 & 15 & 0 & 30 & 1 & 386 \\
\hline Sept & 376 & 0 & 20 & 0 & 23 & 4 & 423 \\
\hline Oct & 309 & 0 & 15 & 0 & 15 & 5 & 344 \\
\hline Nov & 403 & 0 & 15 & 0 & 23 & 10 & 451 \\
\hline Dec & 312 & 0 & 15 & 0 & 10 & 5 & 342 \\
\hline Total & 2987 & 18 & 154 & 0 & 138 & 28 & 3325 \\
\hline
\end{tabular}

Table 3: Monthly outcome indicators (on 6-59 months) - ATFC of CRENAS-Guidan Roumdji region - Niger - $2012 \mathrm{MSFB}$

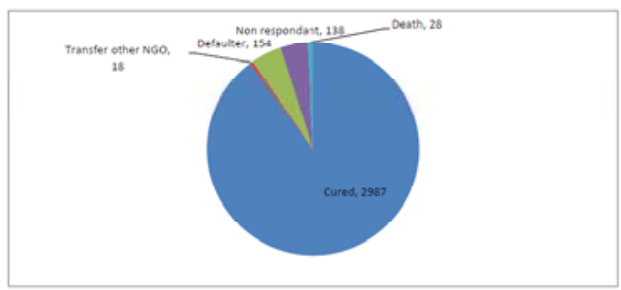

Figure 8: yearly outcome indicators(on 6-59 months)-ATFC

These are elements of changes recorded by the nutritional program and in this case, emphasis is placed on the age group 6-59 months, main target for the reduction of global malnutrition.

\section{1) variables}

The following are considered as variables for the calculation of program outcome:

i) Sum of weight gains (cured 6-59 months)

ii) Sum of lengths of stay (cured 6-59 months)

iii) Number of children for calculation of WG \& LS

iv) Number of children 6 months-14 years vaccinated for measles

v) Total number of cured

vi) Transfer other non-governmental organization

vii) Total number of defaulters

viii) Non-respondents

ix) Deaths

x) Malaria (test + ) rate

xi) Measles cases

xii) Meningitis cases

Tables 7 represents monthly changes in results while table 8 and figure 8 indicate the year 2012 outcomes.

\section{2) Indicators}

The following are main criteria used to evaluate the program and most of them are numerical percentages. 
South American Journal of Public Health

Special Edition May 2016

i) Average weight gain

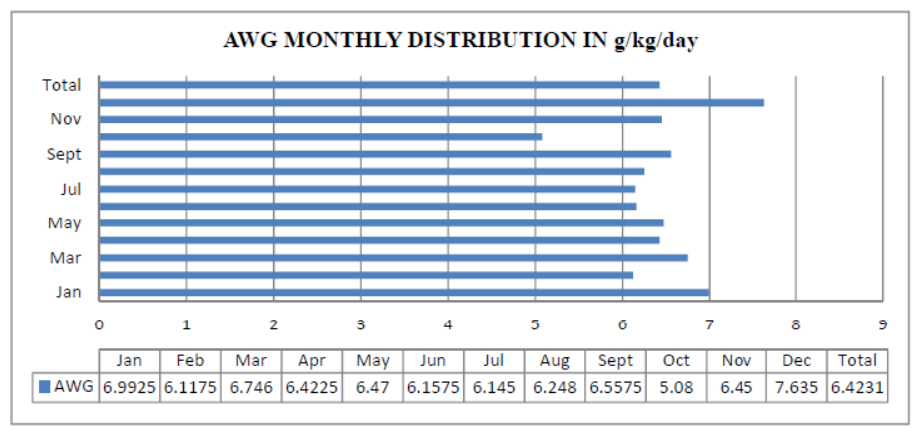

$\mathrm{AWG}=$ Sum of weight gains (cured 6-59 months) divided by number of children for calculation of WG \& LS that is $3340 / 520=6.4230 \mathrm{~g} / \mathrm{kg} / \mathrm{day}$ for the sample.

The normal range is $5-10 \mathrm{~g} / \mathrm{kg} /$ day in a child attending the ATFC. The program recorded $6.42 \mathrm{~g} / \mathrm{kg} / \mathrm{day}$, value that lies within the range and confirmed the indicator was successfully met. The main therapeutic aliment used for treatment was PPN PLUMPY-NUT and total number of sachets was calculated based on the weight and the child next visit day. It is a tick paste and need to be taken with a lot of water. Most children received $1 / 2-1$ sachet times three per day making an average of 12-21 sachets per week. The main challenge here came from the fact that PPN were also sold in the market and some mother sold the children ratios to get money and buy some other food commodities. In some cases, it was shared among all the children including those that were not malnourished.

ii) Average length of stay

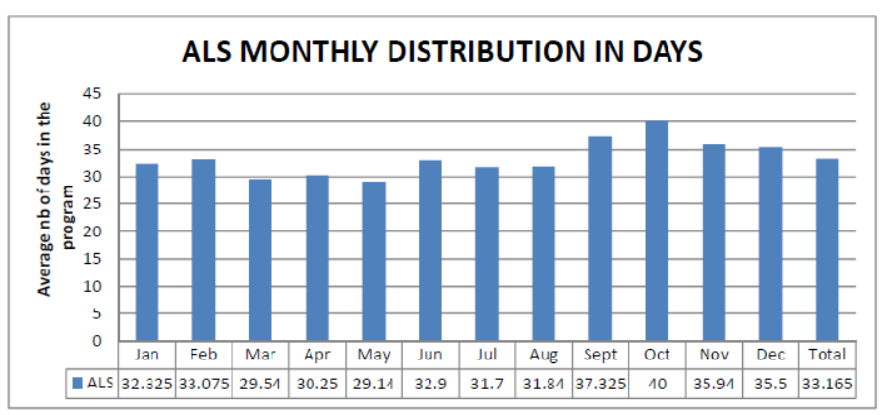

ALS = Sum of lengths of stay (cured 6-59 months) divided by the number of children for calculation of WG \& LS. The cut-off is less than $(<) 45$ days in the ATFC and since program result was 33.16 days, one can confidently declare another success. The exact calculation is $17246 / 520=33.16$ days. The length was calculated from the date of enrollment to the day of discharge. Group counselling were provided at each visit to encourage compliance.

iii) Measles immunization coverage

It is obtained by dividing the number of children 6 months- 14 years vaccinated against measles by the total number of admissions in the 6-59 months. The target is $100 \%$ and it must be noted than no child above 59 months was admitted during the study period. The program score $92.7 \%$ which is below the expected but still stand as a very good result in a region where people still have a lot of prejudice about vaccination. Births are not always registered and the extended program of immunization is yet to be fully implemented by the country. The government with the support of UNICEF supplied vaccines. Doses were administered to children during the first visit if no contraindications to vaccination.

iv) Attendance rate

A result of $96.4 \%$ was recorded and considered a confirmation of the good quality of our services, which were available throughout the day. It is the ratio of children present at distribution over the number of those expected (20126/20880). Children mostly came with 
their mother, sometimes the grandmother and rarely the father. The mother usually brought the children to the ATFC on her way to the marker of when coming back from the market. Friday was somehow a low attendance day because parents went to the mosque, Niger been essentially a Muslim country and this is one of the reason why we could not reach the $100 \%$ limit.

v) Cured rate

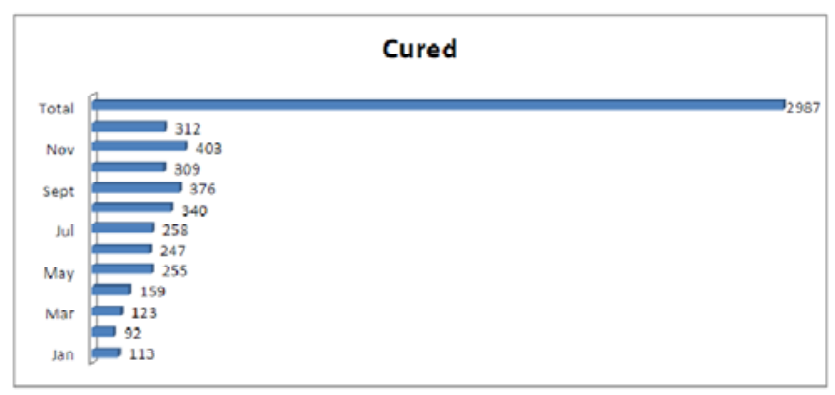

Figure 10: cured rate

It is the proportion of children meeting the discharge criteria over the total number of exits. Exits in this case include cured, transfer other NGO, defaulters, transfer out program, Nonrespondants and deaths.

Exact calculation is $2987 / 3325=0.8983(89.83 \%)$, value above the expected standard of $80 \%$ confirming once again the effectiveness of our program activities.

vi) Defaulter rate

It is calculated as the total number of defaulter over the number of exits as explained earlier, calculated value is $154 / 3325=0.04631(4.631 \%)$ below the standard of $15 \%$ which is the maximum acceptable threshold. Despite the difficulties faced by outreach teams in tracing defaulters, results obtained are still satisfactory.

vii) Death rate

The death rate is $28 / 3325=0.0084(0.84 \%)$ and way below the maximum acceptable value of $3 \%$.

viii) Malaria positivity rate

This was estimated to about $35 \%$ of all the rapid malaria tests performed in the year. The significance of this results lied on the facts that interventions to control the spread of malaria such as the distribution of mosquitos' nets and repellents, indoor as well as outdoor fumigation, and the distribution of antimalarial prophylaxis were usually accelerated as soon as the percentage rose up to $15 \%$. Good monitoring averted dreadful malaria complications in children. It is important to note that during the raining season (June-October), the positivity was more that $15 \%$ and several children received COARTEM (Arthemeter+Lumefanthrine) as part of their treatment. The rapid tests (PARACHECK) were known to have a good sensitivity up to $90 \%$ thus very indicated for malaria screening. Paramedics were trained to read the results adequately and only after 15 minutes as indicated in the standards procedures.

ix) Measles incidence

No case of measles was recorded all through, incidence was thus $0 \%$. The pathognomonic Koplit spots were sought in children presenting with rash and upper respiratory tracts infections. Measles vaccination campaigns carried out together with the ministry of health accounted for some of the success.

$\mathrm{x})$ Meningitis incidence

Despite the facts that Niger is part of the meningitis belt, there was no confirmed case in 2012 I personally suspected three cases when working in the ITFC but the cerebrospinal fluids yielded negative results. I got some information from the team presently there that a serious epidemic of meningitis hit the region during the dry season this year. MSFB has recently, with the approval of some governments, introduced Pentavalent vaccine in its under 5 programs worldwide. 
South American Journal of Public Health

Special Edition May 2016

MORBIDITY

\begin{tabular}{llllll}
\hline Disease & Morbidity & & & & \\
\hline & $<6$ months & $6-59 \mathrm{~m}$ & $>=5 \mathrm{y}$ & Total & $\%$ \\
\hline Malaria & 1 & 679 & 0 & 680 & 0.325827 \\
\hline ARI & 0 & 547 & 0 & 547 & 0.262099 \\
\hline Watery Diarrhea & 0 & 586 & 0 & 586 & 0.280786 \\
\hline Bloody diarrhea & 0 & 0 & 0 & 0 & 0 \\
\hline UOF & 0 & 9 & 0 & 9 & 0.004312 \\
\hline Measles & 0 & 0 & 0 & 0 & 0 \\
\hline Susp. Meningitis & 0 & 0 & 0 & 0 & 0 \\
\hline Anemia & 0 & 0 & 0 & 0 & 0 \\
\hline Hypothermia & 0 & 0 & 0 & 0 & 0 \\
\hline Hypoglycemia & 0 & 0 & 0 & 0 & 0 \\
\hline Shock & 0 & 0 & 0 & 0 & 0 \\
\hline Severe dehydration & 0 & 0 & 0 & 0 & 0 \\
\hline TB & 0 & 0 & 0 & 0 & 0 \\
\hline HIV & 0 & 0 & 0 & 0 & 0 \\
\hline Other & 0 & 265 & 0 & 265 & 0.126977 \\
\hline Total & 1 & 2086 & 0 & 2087 & 1 \\
\hline
\end{tabular}

The commonly reported pathologies were malaria $679(32.6 \%)$, watery diarrhea 586(28.1\%), acute respiratory tracts infections 547(26.2\%), other 265(12.7\%) and UOF $9(0.4 \%)$. The diseases were not life threatening and required no hospital admissions into the intensive therapeutic feeding center. It is worth nothing that MSFB therapeutic protocols include amoxicillin (antibiotic for chest infection), vitamin A( help to limit complications of measles and improves intestinal mucosa regeneration), folic acid ( to prevent anemia ) and Mebendazole for deworming. A five days course of these drugs referred to as systematic treatment is administered on the day of admission into the program to prevent the commonest malnutrition complications, which include diarrhea, pneumonia and Anemia. Worms' infestations are known to be frequent in less than 5 population. Both WHO and the Nigerien ministry of health who also had it in its National protocol approved this.

MORTALITY

\begin{tabular}{lccccc}
\hline Disease & \multicolumn{5}{c}{ Morbidity } \\
\hline Malaria & $<6$ months & $6-59 \mathrm{~m}$ & $>=5 \mathrm{y}$ & Total & $\%$ \\
\hline ARI & 1 & 0 & 0 & 1 & 0.028571 \\
\hline Watery Diarrhea & 0 & 0 & 0 & 0 & 0 \\
\hline Bloody diarrhea & 0 & 0 & 0 & 0 & 0 \\
\hline UOF & 0 & 0 & 0 & 0 & 0 \\
\hline Measles & 0 & 0 & 0 & 0 & 0 \\
\hline Susp. Meningitis & 0 & 0 & 0 & 0 & 0 \\
\hline Anemia & 0 & 0 & 0 & 0 & 0 \\
\hline Hypothermia & 0 & 0 & 0 & 0 & 0 \\
\hline Hypoglycemia & 0 & 0 & 0 & 0 & 0 \\
\hline Shock & 0 & 0 & 0 & 0 & 0 \\
\hline Severe dehydration & 0 & 0 & 0 & 0 & 0 \\
\hline TB & 0 & 0 & 0 & 0 & 0 \\
\hline HIV & 0 & 0 & 0 & 0 & 0 \\
\hline Other & 0 & 0 & 0 & 0 & 0 \\
\hline Total & 6 & 28 & 0 & 34 & 0.971429 \\
\hline
\end{tabular}


28 deaths were reported in the age group of interest and all from unspecified causes not directly related to malnutrition. Investigations carried out by our social workers revealed possible causes of death including ingestion of herbal concoctions, force-feeding resulting to aspiration then death, road traffic accidents and severe burns managed at home. MSFB data collection and management policy requires that those cases be compiled as deaths in the program in as much as children were already enrolled. Probably this also helped to have an overview of the entire health situation of the study area especially the under-five mortality. As shown below most of the deaths occurred 7 days after admission into the program.

\begin{tabular}{llllllllll}
\hline \multicolumn{1}{l}{ Deaths Time since admission } & \multicolumn{7}{l}{ Time of death } \\
\hline & $<6$ & $<5$ & $>=5$ & $\%$ & & $<6$ & $<5$ & $>=5$ & $\%$ \\
& $\mathrm{~m}$ & $\mathrm{y}$ & $\mathrm{y}$ & & & $\mathrm{m}$ & $\mathrm{y}$ & $\mathrm{y}$ & \\
\hline$<48$ hours & 0 & 0 & 0 & 0 & $06.30-10 \mathrm{~h}$ & 0 & 0 & 0 & 0 \\
\hline $48 \mathrm{~h}-7$ days & 2 & 1 & 0 & 0.085714286 & $10-18 \mathrm{~h}$ & 7 & 28 & 0 & 1 \\
\hline$>7$ days & 5 & 27 & 0 & 0.914285714 & $18-23 \mathrm{~h}$ & 0 & 0 & 0 & 0 \\
\hline Total & 7 & 28 & 0 & 1 & $24-06.30 \mathrm{~h}$ & 0 & 0 & 0 & 0 \\
\hline Total & 7 & 28 & 0 & 1 & & & & & \\
\hline$<48$ hours & 0 & 0 & 0 & 0 & $06.30-10 \mathrm{~h}$ & 0 & 0 & 0 & 0 \\
\hline
\end{tabular}

The hypothesis of accidental causes of deaths can thus be retained.

\section{Discussion}

\section{a) Hypothesis testing}

\begin{tabular}{|c|c|c|}
\hline \multicolumn{3}{|c|}{ POPULATION PARAMETRES } \\
\hline & ALS & AWG \\
\hline Jan & 31.9596 & 6.538889 \\
\hline Feb & 30.28283 & 6.181818 \\
\hline Mar & 28.15789 & 6.732794 \\
\hline Apr & 28.69192 & 6.809091 \\
\hline May & 28.86 & 7.276 \\
\hline Jun & 31.155 & 6.606 \\
\hline Jul & 30.955 & 6.4845 \\
\hline Aug & 30.7704 & 8.2468 \\
\hline Sept & 35.395 & 5.5035 \\
\hline Oct & 37.785 & 5.6525 \\
\hline Nov & 35.26 & 6.848 \\
\hline Dec & 34.46 & 7.13 \\
\hline
\end{tabular}

Using the above data and the following online tool https://www.easycalculation.com/statistics/standard-deviation.php, necessary population means as well as standard deviations were generated. Once those two population parameters were available and together with the sample statistics below, all tests, statistics were calculated with the help of another online tool known as http://insilico.net/tools/statistics/ztest. The summary of all the study statistics is available one of the table below.

\begin{tabular}{cc}
\hline SAMPLE STATISTICS & \\
\hline Sum total expected at each distribution & $\mathbf{2 0 8 8 0}$ \\
\hline Sum total present at each distribution & $\mathbf{2 0 1 2 6}$ \\
\hline Number choice & $\mathbf{5 8}$ \\
\hline Number transfers due to long stay & $\mathbf{2 6}$ \\
\hline Sum of weight gains (cured 6-59m) & $\mathbf{3 3 4 0}$ \\
\hline Sum of lengths of stay (cured 6-59m) & $\mathbf{1 7 2 4 6}$ \\
\hline Number of children for calculation of WG \& LS & $\mathbf{5 2 0}$ \\
\hline Number children 6m - 14y vaccinated for measles & $\mathbf{2 4 6 9}$ \\
\hline
\end{tabular}


South American Journal of Public Health

Special Edition May 2016

\begin{tabular}{cc}
\hline \multicolumn{2}{c}{ Number Direct admissions ATFC } \\
\hline Total beneficiaries in ATFC \\
\hline \% Direct admissions ATFC \\
\hline Attendance rate & $\mathbf{0 . 9 6 3 8 8 8 8 8 9}$ \\
\hline Measles immunization coverage & $\mathbf{0 . 9 2 7 4 9 8 1 2 2}$ \\
\hline Average weight gain $(\mathrm{g} / \mathrm{kg} / \mathrm{d}) 6-59 \mathrm{~m}$ & $\mathbf{6 . 4 2 3 0 7 6 9 2 3}$ \\
\hline Average length stay (days) $6-59 \mathrm{~m}$ & $\mathbf{3 3 . 1 6 5 3 8 4 6 2}$ \\
\hline
\end{tabular}

STUDY STATISTICS SUMMARY

\begin{tabular}{|c|c|c|}
\hline & $\begin{array}{l}\text { AVERAGE LENGTH OF } \\
\text { STAY (ALS) }\end{array}$ & $\begin{array}{l}\text { AVERAGE WEIGTH GAIN } \\
\text { (AWG) }\end{array}$ \\
\hline \multicolumn{3}{|l|}{ HYPOTHESIS } \\
\hline $\mathrm{H} 0$ & $\mu$ als(pop) $=\mu$ als(sample) & $\mu a w g($ pop $)=\mu a w g($ sample $)$ \\
\hline $\mathrm{H} 1$ & $\mu$ als(pop) $\neq \mu$ als(sample) & $\mu a w g($ pop$) \neq \mu a w g($ sample) \\
\hline \multicolumn{3}{|l|}{ CALCULATOR } \\
\hline $\begin{array}{l}\text { Population Mean: } \\
\mu \text { (pop) }\end{array}$ & 31.925 days & $6.6787 \mathrm{~g} / \mathrm{kg} / \mathrm{day}$ \\
\hline $\begin{array}{l}\text { Sample Mean: } \\
\mu(\text { sample })\end{array}$ & 33.165 days & $6.423 \mathrm{~g} / \mathrm{kg} / \mathrm{day}$ \\
\hline $\begin{array}{l}\text { Population } \\
\text { Standard deviation: } \\
\text { (б) }\end{array}$ & 2.87464 & 0.57609 \\
\hline Sample size & 520 & 520 \\
\hline Alpha : $\alpha$ & 0.05 & 0.05 \\
\hline Tail side & Left & Right \\
\hline \multicolumn{3}{|l|}{ RESULTS } \\
\hline Z-value & 9.8366 & -10.123 \\
\hline One tail $p$-value & $>0.9999$ & $>0.9999$ \\
\hline $\begin{array}{l}\text { 95\% Confidence } \\
\text { Interval }\end{array}$ & [inferior, 32.1323] & [6.6372, inferior] \\
\hline Decision & Failure to reject $\mathrm{HO}$ & Failure to reject $\mathrm{HO}$ \\
\hline Translation & $\begin{array}{l}\text { Both the population and the } \\
\text { sample are not significantly } \\
\text { different. }\end{array}$ & $\begin{array}{l}\text { Both the population and the } \\
\text { sample are not significantly } \\
\text { different. }\end{array}$ \\
\hline Conclusion & $\begin{array}{l}\text { Sample successful indicators } \\
\text { can be generalized to the entire } \\
\text { population. }\end{array}$ & $\begin{array}{l}\text { Sample successful indicators can } \\
\text { be generalized to the entire } \\
\text { population }\end{array}$ \\
\hline Extrapolation & $\begin{array}{l}\text { Children didn't overstay in the } \\
\text { program }\end{array}$ & $\begin{array}{l}\text { Children gained the expected } \\
\text { weight while in the program }\end{array}$ \\
\hline
\end{tabular}

b) Impact of curative treatment on the fight against hunger

In the light of above population observations and hypothesis testing, it is clear the curative program has a positive impact on the population receiving it. On the fight against hunger the main effect is a direct the reduction of the incidence and prevalence of global as well as moderate malnutrition.

On a personnel level, it prevents morbidities and mortalities directly associated with malnutrition such as pneumonia, dehydration, shock, sepsis, tuberculosis, skin diseases, etc. Long-term effects have been shown to reduce the incidence of mental retardation as children suffering from chronic malnutrition sometimes develop this pathology. After recovering from malnutrition, some children who exhibited antisocial behaviors such as social isolation resume game activities with their peers. Attendance at school also rises in those children that attended the ambulatory therapeutic feeding center once discharged. Education will improve their understanding, might fletch them a job, reduce or limit the degree of poverty, improve 
their access to some services, increase their purchase power and protect them from lacking food and suffer from hunger.

In the community, there is an improvement on the under-5 as well as the general population mortality rates. Communities are thus empowered and ready to develop some activities such as agriculture that will further improve their food safety and reduce their reliance towards external aids or donors. Reducing malnutrition in a community also help fight a social stigma, improve self-confidence and increase the chances to success as a group. Countries were malnutrition is rampant spend a lot of money on treatment through the development and management of therapeutic feeding centers, adequate treatment reduces the number of patients and staffs thus saving a lot of money which when properly redirected could serve in the fight against malnutrition.

b) Proposed protocols for tracing of defaulters

Considering the risk defaulting represents for the success of curative treatment and based on information obtained from the files I reviewed the below protocol was put into place to at the same time prevent and manage defaulters cases.

1. The following behaviours in a parent/guardian accompanying a malnourished child to the ATFC should be considered as high risks signs. These should be sougth for by anybody working in an ATFC.

(i) Lack of interest towards the sick child

(ii) evidence of rejection or abuse on the sick child

(iii) refusal to associate with other parent while in the ATFC

(iv) signs of depression such as anxiety, excessive complaints, cry or excessive tiredness

(v) Discouragement over the child health status

(vi) Complaint over the treatment prolongation

2. Management of a potential case

(i) inform the social worker, the nurse and the doctor in charge of the patient.

(ii) encourage the social workers to have as many private counselling sessions as possible with the parent. In those sessions he/she should reassure, encourage and regularly follow up the mother. The health status of the malnourished child should constantly be reported to her and any smallest improvement must be emphasized as a positive sign. While visiting the ambulatory therapeutic feeding center the mother should be encourage to involve herself in some occupationnal activities such asembrodery.

3. Management of a confirmed case

(i) Retrieve the patient case folder and collect information towards her/his condition, the guardian names and address and the date of admission.

(ii) Request for transportation and inform the project coordinator of the planned movement

(iii) Travel to the patient address to found out about the reason for defaulting

(iv) Write a report about the case and submit to the community outreach department team leader

(d) Societal role in preventing default

Within the context of Niger and in relation to the various causes enumerated earlier in observations it is clear that a reasonable solution for the prevention of default is women empowerment in Niger. The society need to give them more responsibility and encourage gender equality. The women should also be considered for education in order for them to improve their knowledge and their decision power. Society should recognize the damages teenage marriages has done in terms of maternal and infant mortality. Educated women stand a better chance to protect their children against malnutrition whose imminent signs are well thought in all general curriculum. Force marriages especially with elderly men as frequent in Niger, create a malaise in women who might transfer all the bitterness generated by such setup to their sick malnourished children and fail to provide them with the necessary support 
needed throughout the entire therapy. An empowered woman can decide on the total number of children she wants to have thereby avoiding multiple pregnancies which sometimes set a precedence for malnutrition in some of the them. Family planning is still considered taboo in Niger where polygamy is the norm as majority of the society is Muslim. When the society will decides to embrace birth control methods and allow the woman to have control over this issue, the number of defaults in relation to the lack of nannies at home will also reduce. In Niger the men control the product of harvest which they sometimes decide to sell for money without consulting the women who are responsible for the family menu. Women should be supported and allowed to choose from those products and with additional education and exposure they will be able to prepare menus that are recommended by dieteticians and prevent malnutrition in their children without which there will not be defaults.

\section{Conclusion}

There should be a synergy between prevention and treatment in the fight against hunger. Both should be applied systematically with prevention been the primary intervention. Dissociating them will yield results that are not sustainable on the long-term. Prevention can be achieved through several activities such as agriculture and funding but of utmost importance in our study area is women empowerment which is loaded with the potential of controlling birth, reduce teenage pregnancies and force marriage, improve household incomes and satisfy dietary requirements. An educated woman will follow up her child treatment until the end and this will minimize default. Society thus has a big role to play as rules and laws applying to women are sometimes fixed by the society, which is generally dominated by men.

On the order hand curative treatment, helps control acute cases, necessary step needed to reduce the population morbidity and mortality through the diminution of the moderate as well as global acute malnutrition rates. In as much as curative treatment are recommended, care should be taken to decide who should be given the priority for such activities. In the context of our study, we demonstrated that the international medical organization, Medicines Sans Frontieres (MSF) also known as doctors without borders is one of those non-governmental organizations with experience in the fight against malnutrition. The nutritional program ran by them within the study area was sanctioned by good results as evidence by the success they achieve in their indicators and adequate hypothesis testing confirmed the fact that this success can be extended to our study sample.

The United Nations in this year general assembly confirmed some successes in achieving the first millennial goal fixed in 2000 and dealing with the reduction of poverty and hunger. Globally there is progress but this now has to contain with a new threat to hunger, which is just becoming clear to us that is Climate Change.

\section{Recommendations}

1) Niger government should properly screen all the non-governmental organizations running interventions on malnutrition, and should only allow those one that have been tested as efficient in running effective activities.

2) Niger government should regularly supervise the activities of acting organizations to ensure that their activities are in line with the national policy as well as the world health organization.

3) Government should regularly monitor and evaluate such program in order to keep them on track.

4) Hierarchies of active organizations should concentrate more on the welfare of the populations they are serving rather than the wellbeing of their staffs' members.

5) All countries affected by malnutrition should define national policies that will in details explain the management of affected cases, livelihood activities to invest on and practical preventive measures.

6) In the future malnutrition management should be redirected towards a community approach that will largely implicate the family, the community and the society. 
7) Niger national assembly should enact several laws that protect females e.g. abolition of teenage marriage.

8) A progressive reproductive health policy must be put in place and all country stakeholders must support its implementation.

9) More efforts should be made to convince parents over gender equality when it comes to education, with the females having the same right to education as the males.

10) New strategies should be developed to prevent and control consequences of climate change as this represents the greatest future threat for countries in the Sahel region such as Niger.

\section{Project Summary}

From the $2 / 1 / 2012$ to $30 / 12 / 2012$ while working as an expatriate medical doctor with the international medical organization Medicines Sans Frontieres also known as doctors without borders, i completed the management of 3325 malnourished children aged 6-59 months in Guidam Roumdji Niger Republic.

A total population number of 2987 were declared cured, 18 were transferred to other NGO, 154 defaulted, 138 didn't respond to treatment and 28 died.

In May 2012, I requested MSF to forward the complete data to me for my Master of public health and my request was grated after several discussions with the headquarters in Belgium, Luxembourg and Italy.

I therefore together with my approved supervisor, designed a retrospective study based on a sample of 520 cured children, whose main aim was to prove or demonstrate the need to combine curative treatment and preventive societal measures to succeed in the fight against malnutrition in the Niger republic.

The research design was submitted to the university in July 15 and got approval for a go ahead in September 15

The population outcome indicators (cured rate, average length of stay, average weight gain, defaulter rate etc.) were all satisfactory. Using two online tools (in-silico and easycalculation.com) for statistics calculation, under 5\% significance, subsequent two-tails zests failed to reject that the two most important nutritional sample statistics (average weight gain and average length of stay) were equal to their population counterpart. The nutritional program was thus effective.

A further qualitative study of the defaulter rate revealed the importance of prevention, which can be greatly improved through women empowerment in Niger since the mothers should naturally be the ones in charge of the family menu and are generally involved in the care of their sick children.

Prevention and cure cannot be separated if we intend to eliminate malnutrition in Niger and the world.

The United Nations recently confirmed an improvement in the millennium developmental goal dealing with the reduction of hunger and poverty but a new threat of climate change, which we must tackle will draw us back if nothing is done.

\section{References}

[1.] BLÖSSNER, 2005, Malnutrition Quantifying the health impact at the national and local level. Environmental Burden of Diseases Series, No 12

[2.] (C) Douglas Harper 2015, etymonline.com, (C) 2001-2005 Douglas Harper, Custom Logo Design

[3.] Golden, 2002, History of Food and Nutrition In Emergency Relief, The Development of the concept of malnutrition, Michael H.N. Golden

[4.] Harper Collins 2004, Collins English Dictionary , Harper Collins 2004

[5.] Harris \& Drimmie, 2012, Toward an integrated approach for addressing malnutrition in Zambia , IFPRI ( International food policy research institute) Discussion paper 01200 August 2012

[6.] Houghton Miffin Company, 2005, The American Heritage ${ }^{\circledR}$ New Dictionary of cultural literacy, Third edition. Houghton Miffin Company , 2005 
South American Journal of Public Health

Special Edition May 2016

[7.] Potts \& Gidi \& Campbell \& Zureich , 2011 , Niger : Too little, Too late. Malcom Potts, Virginia Gidi, Martha Campbell and Sarah Zureick, International Perspectives on Sexual and Reproductive health, Volume 37, Number 2, June 2011.

[8.] Potts \& Gidi \& Campbell \& Zureich, as cited by Turner 2011, Niger : Too little, Too late. Malcom Potts, Virginia Gidi, Martha Campbell and Sarah Zureick, International Perspectives on Sexual and Reproductive health, Volume 37, Number 2, June 2011.

[9.] (C) Random House. Inc 2015 "Malnutrition". Dictionary.com Unabridged, Random House , Inc, 2015

[10.] UNICEF , 2010 , Facts for life , 4th edition UNICEF

[11.] Young, 2012, Food and development, Abingdon, Oxon : Routledge .

\section{Bibliography}

[1.] American Heritage ${ }^{\circledR}$ Stedman's medical dictionary

[2.] Collins English dictionary

[3.] https://www.easycalculation.com/statistics/standard-deviation.php

[4.] http://in-silico.net/tools/statistics/ztest

[5.] How to weigh and measure children: Assessing the Nutritional Status of Young Children, United Nations, 1986

[6.] Institut National de la statistique. Le Niger en chiffres 2011 p. 24

[7.] MSF Data base CRENAS-Guidam Roumdji 2012

[8.] MSF ATFC Nutritional guide

[9.] < Niger: Too Little, Too Late> is an article by Malcolm Potts, Virginia Gidi, Martha Campbell and Sarah Zureick.

[10.] Online etymology dictionary, (C) 2010 Douglas Harper

[11.] CRandom House, Inc.20153

[12.] Towards an integrated approach for addressing malnutrition in Zambia4>, Joddy Harris and Scott Drimie

[13.] Young, E.M. 2012. Food and development 